\title{
Agricultural Wastes as Low Cost Adsorbents for Pb Removal: Kinetics, Equilibrium and Thermodynamics
}

\author{
Kafia M. Shareef Surchi \\ Department of chemistry, College of Sciences, University of Salahaddin, Hawler, Kurdistan \\ Tel: 964-750-455-8666_E-mail: Kafia.surchi@yahoo.com
}

Received: January 24, 2011 Accepted: February 14, 2011 doi:10.5539/ijc.v3n3p103

\begin{abstract}
In this study, removal of poisonous $\mathrm{Pb}$ (II) from artificially contaminated water has been investigated with the aim of detoxifying industrial effluents before their safe disposal onto land or into river waters. Five low-cost natural adsorbents, chalf, rice husk, sesame, sun flower and tea waste, were used to remove $\mathrm{Pb}$ from synthesized waste water. Kinetic study revealed that pseudo-first order model is suitable to explain our experimental data and intraparticle transport is not the only rate-limiting step. The adsorption equilibrium data correlate well with Freundlich model with regression, $\mathrm{R}^{2}$, range from $0.947-0.993$. The results showed that efficiencies of chalf, rice husk, sesame husk, sun flower husk and tea waste for $\mathrm{Pb}$ ion removal were $85 \%, 90 \%, 100 \%, 86 \%, 98 \%$ repectively. High adsorption capacity of the tested adsorbents makes it preferable and very attractive alternative adsorption material. This field may therefore be utilized by developing countries to alleviate or at least, reduce the impacts of industrial water pollution on the aquatic environment.
\end{abstract}

Keywords: Adsorption, $\mathrm{Pb}(\mathrm{II})$, Agricultural wastes, Low cost adsorbents, Adsorption isotherms

\section{Introduction}

Water used in industry creates a wastewater that has a potential hazard for our environment because of introducing various contaminants such as heavy metals into soil and water resources. Heavy metal ions are nowadays among the most important pollutants in surface and ground water (Brinzo, et al., 2009). The safe and effective disposal of industrial wastewater is thus a challenging task for industrialists and environmentalists. The important toxic metals are $\mathrm{Cd}, \mathrm{Zn}, \mathrm{Pb}$ and $\mathrm{Ni}$. Nowadays, with the exponential increase in population, measures for controlling heavy metal emissions into the environment are essential (Mousavi, et al., 2010, Maximous N., et al., 2010). Lead causes many serious disorders like, anemia, kidney disease, nervous disorders, and even death, it heads the toxic element list of 2008 (Karthika, et al., 2010).

At present lead pollution is considered a worldwide problem because this metal is commonly detected in several industrial wastewaters (Davydova, 2005).Undoubtedly, industrial waste based adsorbents offer a great promise for commercial purposes. Solid wastes are a vexing societal problem mandating attention to recycling. Recycled product quality is not always high or recycle may not be feasible. However, conversion of solid wastes into effective low-cost adsorbents for wastewater treatments could decrease costs for removing lead.

New approaches based on the use of natural inexpensive adsorbents for treatment have been reported (Badmus, et al., 2007). In general, an adsorbent can be termed as a low cost adsorbent if it requires little processing, is abundant in nature, or is a by-product or waste material from another industry (Nasim, et al., 2004).

In kurdistan, huge amounts of chalf, rice husk, sesame husk, sun flower husk and tea waste were generated daily, which create environmental and disposal problems. Therefore, application of these wastes as adsorbent offers highly effective technological means in dealing with pollution of heavy metals and solving there disposal problems, with minimum investment required (Najua, et al., 2008; Malakootian, et al., 2009).

Therefore there is an urgent need that all possible sources of agro-based inexpensive adsorbents, in Kurdistan, should be explored and their feasibility for the removal of heavy metals should be studied in detail. The objective of this study is to contribute in the search for less expensive adsorbents and their utilization possibilities for various agricultural waste by-products which are in many cases also pollution sources.

However, to the best of our knowledge, no such study has been done in kurdistan. Based on this fact the present study was proposed to evaluating the applicability and the efficiency of the newly chosen agricultural wastes as 
natural adsorbents such as chalf, rice husk, sesame husk, sun flower husk and tea waste in water purification. The use of these locally available agricultural for removal of lead from aqueous solutions at different experimental conditions is an alternative waste management or environmental conservation.

\section{Materials and methods}

\subsection{Materials}

All the chemicals used were of analytical grade reagent. A stock solution of lead nitrate $(1000 \mathrm{mg} / \mathrm{L})$ was used as adsorbate and solutions of various concentrations $(15,25,50,75 \& 100 \mathrm{mg} / \mathrm{L})$ were obtained by diluting the stock solution with distilled water. The detailed procedure for the preparation of rice husk, sesame husk and sun flower husk are reported in literature (Huda \& Kafia, 2010; Huda, 2011). Chalf and tea waste were washed at the first step and then rinsed with distilled water. After drying at $100{ }^{\circ} \mathrm{C}$, it was ground and screened (using screen with mesh size 40) and kept in plastic containers before the time of use (Amir, et al., 2005).

\subsection{Adsorption experiments: Kinetics and isotherms}

Pilot experiments were done to determining the right adsorbent mass ( $0.08 \mathrm{~g})$ particle size (40 mesh), and contact (120 min), that will bring about a better decontamination of $\mathrm{Pb}$-contaminated aqueous solutions.

In the kinetic experiments for $\mathrm{Pb}(\mathrm{II})$ adsorption, $0.08 \mathrm{~g}$ of dry adsorbent was mixed with $10 \mathrm{ml}$ of $\mathrm{Pb}$ (II) solution. Batch experiments were carried out by mixing metal solution with concentration of $15,25,50$, and $75 \mathrm{mg} / \mathrm{L}$ with each adsorbent in a shaker water bath with $125 \mathrm{rpm}$ at $25{ }^{\circ} \mathrm{C}$ for $10,20,30,60,90,120,180,240$, and $300 \mathrm{~min}$. The adsorbent and adsorbate suspensions were separated by centrifugation at $3000 \mathrm{rpm}$ for $10 \mathrm{~min}$ (Hemn \& Kafia, 2009; Kafia \& Georg, 2008; Hewa \& Kafia, 2010).

The isotherm experiments were carried out using $0.08 \mathrm{~g}$ of dry adsorbent at initial $\mathrm{Pb}(\mathrm{II})$ concentration of 15,25 , 50,75 , and $100 \mathrm{mg} / \mathrm{L}$, allowing sufficient time, $300 \mathrm{~min}$, for adsorption equilibrium, So further experiments were conducted at $300 \mathrm{~min}$ of contact. Thermodynamic study of adsorption experiments were performed following the same procedure at 15,25 and $35^{\circ} \mathrm{C}$.

The supernatants were filtered through Whatman \#42 filter paper. The remaining lead concentration was analyzed using PYE Unicom spq. Atomic Absorption Spectrophotometer (372469, England). All the experiments and analysis have been carried out in duplicate and the maximum analytical error was found to be less than $5 \%$. The adsorbed phase concentration $\left(\mathrm{q}_{\mathrm{t}}, \mathrm{mg} / \mathrm{g}\right)$ was calculated using the following equation (Nassar, 1997):

$$
\mathrm{q}_{\mathrm{t}}=\frac{\mathrm{C} \circ-\mathrm{Ct}}{m} * V
$$

Where $\mathrm{C}_{\mathrm{o}}$ \& $\mathrm{C}_{\mathrm{t}}$ are the initial and the final lead concentration $(\mathrm{mg} / \mathrm{L})$ respectively; $\mathrm{V}$ is the water sample volume $(\mathrm{L})$; and $\mathrm{m}$ is the mass of adsorbent used ( $\mathrm{g}$ ).

\section{Results and Discussion}

\subsection{Adsorption kinetics}

\subsubsection{Effect of contact time}

Fig. 1 shows the effect of contact time on $\mathrm{Pb}$ ion uptake by the selected adsorbents. This was achieved by varying the contact time from 10 to $300 \mathrm{~min}$. in separate experiment runs. Equilibrium contact time was found to be $120 \mathrm{~min}$. The removal rate of $\mathrm{Pb}$ gradually decreased with increase in contact time. Initially, the rate of $\mathrm{Pb}$ uptake was higher because all sites on the adsorbent were vacant and $\mathrm{Pb}$ concentration was high, but decrease of sorption sites reduced the uptake rate. Similar results were found in the study of Mousavi et al. (2010).

\subsubsection{The effect of initial $\mathrm{Pb}$ ion concentration}

The effect of initial $\mathrm{Pb}$ ion concentrations on the adsorption efficiency of the studied agricultural wastes is shown in Fig. 1. Adsorption experiments were carried out at different initial $\mathrm{Pb}$ concentrations ranging from 15 to 100 $\mathrm{mg} / \mathrm{L}$. It was observed as a general trend that there is a decrease of the removal percentage with increase in initial concentration from 15 to $100 \mathrm{mg} / \mathrm{L}$. These results may be explained on the basis that the increase in the number of ions competing for the available binding sites and also because of the lack of active sites on the adsorbent at higher concentrations. Therefore, more metal ions were left un-adsorbed in solution at higher concentration levels (Krishnan \& Anirudhan, 2003). 


\subsubsection{Kinetic Models}

Kinetics of adsorption is an important characteristic in defining the efficiency of adsorption. The pseudo-first order (Lagergren's rate) model is the one most widely used for the adsorption of a solute from a liquid solution (Lagergren, 1898). The linear form of the pseudo-first order equation is given by:

$$
\log \left(\mathrm{q}_{\mathrm{e}}-\mathrm{q}_{\mathrm{t}}\right)=\log \mathrm{q}_{\mathrm{e}}-\frac{k}{2.303} t
$$

Where $\mathrm{k}$ is the pseudo-first order rate constant. The slope and intercepts of the plot of $\log \left(\mathrm{q}_{\mathrm{e}}-\mathrm{q}_{\mathrm{t}}\right) \mathrm{vs}$. $\mathrm{t}$ (Fig. 2) for adsorption of $\mathrm{Pb}$ on sesame were used to determine the value of $\mathrm{k}$ and $\mathrm{q}_{\mathrm{e}}$ respectively. Values of correlation coefficient $\left(\mathrm{R}^{2}\right)$ together with the small difference between the experimental and the calculated values of $\mathrm{q}_{\mathrm{e}}$ (Table 1) indicated that pseudo-first order model is suitable to explain our experimental data. Values of $\mathrm{k}$ for removal of $\mathrm{Pb}$ ions by sesame were: $0.0313,0.0253,0.0345, \& 0.0267$. Our results were in agreement with those reported in literature (Karthika, et al., 2010).

\subsubsection{Adsorption mechanism}

When the water sample is shaken, the adsorbate species, i.e. lead, are transported to the solid phase by the intraparticle transport phenomenon. The intraparticle transport is supposed to be the rate controlling step. The rate of particle transport through this mechanism is slower than adsorption on the exterior surface site of the adsorbent. The amount of adsorbed species, lead, varies proportionately with a function of retention time. The equation can be expressed as (Badmus, et al., 2007):

$$
\mathrm{q}_{\mathrm{e}}=\mathrm{k}_{\mathrm{d}} \mathrm{t}^{1 / 2}+\mathrm{C}
$$

Where $k_{d}$ is the constant coefficient, the initial rate of intraparticular diffusion $\left(\mathrm{mg} / \mathrm{L} . \min ^{1 / 2}\right)$. Probably, the transport of the water sample through the particle-sample interface into the pores of the particles, as well as the adsorption on the available surface of the adsorbents, is responsible for adsorption. Fig. 3 illustrates the diffusion of $\mathrm{Pb}$ ions within the sesame as a function of time and shows that intraparticle diffusion occurred in three stages. The ions diffused quickly among the particles at the beginning of the adsorption process, and then intraparticle diffusion slowed down and stabilized. The slight deviation of these lines from origin indicates that intraparticle transport is not the only rate-limiting step (Badmus, et al., 2007). Based on these results it appears that the $\mathrm{Pb}$ removal by chalf, rice husk, sesame, sun flower and tea waste may be controlled by chemisorption process, or by a combination of both physical and chemical process.

\subsection{Adsorption isotherms}

The most common representation of the adsorbate concentration and quantity of material adsorbed is the adsorption isotherm; graph of the amount adsorbed against the equilibrium concentration, at a specific temperature. The nature of the interaction between the adsorbate and adsorbent, i.e. favorable or unfavorable, can be determined from the isotherm shape (Khraisheh, et al., 2004).

\subsubsection{Langmuir Isotherm}

The model is applicable in the cases where only one molecular layer of adsorbate is formed at the adsorbent surface. which remains constant even at higher adsorbate concentrations. The Langmuir equation can be presented by the well-known equation (Allen, et al., 1995):

$$
\frac{C e}{q e}=\frac{1}{q \max \mathrm{kl}}+\frac{1}{\mathrm{qmax}} \mathrm{C}_{\mathrm{e}}
$$

Where $\mathrm{q}_{\max }$ is the monolayer adsorption capacity of the adsorbent $(\mathrm{mg} / \mathrm{g})$ it is the maximum amount adsorbed, $\mathrm{k}_{\mathrm{L}}$ is the Langmuir adsorption constant $(\mathrm{L} / \mathrm{mg}), \mathrm{C}_{\mathrm{o}}$ is the equilibrium metal ion concentration in the solution $(\mathrm{mg} / \mathrm{L})$ and $\mathrm{q}_{\mathrm{e}}$ is the equilibrium metal ion concentration on the adsorbent $(\mathrm{mg} / \mathrm{g})$. Values of $\mathrm{q}_{\max }$ and $\mathrm{K}_{\mathrm{L}}$ are calculated respectively from the slope and the intercept of plot of $\mathrm{C}_{e} / \mathrm{q}_{\mathrm{e}} \mathrm{vs} . \mathrm{C}_{\mathrm{e}}$, as shown in figure 4 . Value of Langmuir parameters and $\mathrm{R}^{2}$ were summarized in table 1 . Values of $\mathrm{K}_{\mathrm{L}}$ for removal of $\mathrm{Pb}$ ions by chalf, rice husk, sesame husk, sun flower husk and tea waste were $0.123,0.208,0.091$ and 0.221 respsctively.

The Langmuir isotherm assumes monolayer adsorption onto a surface containing a finite number of adsorption sites of uniform strategies of adsorption with no transmigration of adsorbate in the plane of surface. Monolayer adsorption is distinguished by the fact that the amount adsorbed reaches a maximum value at a moderate 
concentration; this corresponds to complete coverage of the adsorbent surface by a monomolecular layer of adsorbate (Khraisheh, et al., 2004).

\subsubsection{Freundlich Isotherm}

This model proposes heterogeneous energetic distribution of active sites, accompanied by interaction between adsorbed molecules. The Freundlich linear form is given by the following equation.

$$
\log \mathrm{q}_{\mathrm{e}}=\log \mathrm{K}_{\mathrm{F}}+\frac{1}{n} \log \mathrm{C}_{\mathrm{e}}
$$

Where $\mathrm{K}_{\mathrm{F}}$ is a constant related to the adsorption capacity (Freundlich constant) and $1 / \mathrm{n}$ is an empirical parameter related to the adsorption intensity (which varies with the heterogeneity of the material). Values of $1 / \mathrm{n}$ and $\mathrm{K}_{\mathrm{F}}$ are calculated respectively from the slope and the intercept of plot of $\mathrm{C}_{\mathrm{e}} / \mathrm{q}_{\mathrm{e}} \mathrm{vs} . \mathrm{C}_{\mathrm{e}}$, is shown in figure 5 . Freundlich parameters together with $\mathrm{R}^{2}$ were summarized in table 4 . Values of $\mathrm{K}_{\mathrm{F}}$ for removal of $\mathrm{Pb}$ ions by chalf, rice husk, sesame husk, sun flower husk and tea waste were 1.119, 1.195, 1.790, 1.138 and 2.248 respectively.

It will be noted that the value of $1 / \mathrm{n}$ was between 0 and 1 indicating that the sorption of $\mathrm{Pb}$ ions into the studied adsorbents was favorable under the mentioned conditions. This Freundlich type behavior is indicative of the surface heterogeneity of the adsorbents, i.e. the adsorptive sites (surface of the studied adsorbents) are made up of small heterogeneous adsorption patches that are homogeneous in themselves. The activation of adsorption site takes place, leading to increased adsorption probably through the surface exchange mechanism.

\subsubsection{Temkin Isotherm}

Temkin model assumes effect of some indirect interactions amongst adsorbate particles and suggests linear decrease in the heat of adsorption of all the molecules in the layer, due to these interactions. Temkin linear isotherm form is expressed as follows (Mittal, 2009):

$$
\mathrm{q}_{\mathrm{e}}=\mathrm{a}_{\mathrm{t}}+2.303 \mathrm{~b}_{\mathrm{t}} \log \mathrm{C}_{\mathrm{e}}
$$

Where $a_{t}$ and $b_{t}$ are Temkin constant. Values of $a_{t}, b_{t}$ are calculated respectively from the intercept and the slope of the plot of $q_{e}$ vs. $\log C_{e}$ (Fig. 6). Values of $a_{t}$ were in the range of $0.218-2.342$, while values of $b_{t}$ in the range of $0.975-1.302$.

The experimental data for the uptake of $\mathrm{Pb}$ ions by chalf, rice husk, sesame husk, sun flower husk and tea waste were explained using three of the most widely used adsorption isotherms: Langmuir, Freundlich and Temkin isotherms. The data were found to best fit the Freundlich isotherm model.

\subsection{Adsorption thermodynamics}

The thermodynamics for $\mathrm{Pb}$ ion removal by sesame was investigated in temperature range of 298-308 K, and the influence of temperature on the adsorption capacity is shown in Fig. 7. It can be found that there is an increase in the adsorption capacity of sesame with the temperature increase. Thermodynamic parameters such as change in Gibbs free energy $(\Delta \mathrm{G})$, enthalpy $(\Delta \mathrm{H})$ and entropy $(\Delta \mathrm{S})$ were determined using the following equation:

$$
\begin{gathered}
\mathrm{K}_{\mathrm{D}}=\mathrm{q}_{\mathrm{e}} / \mathrm{C}_{\mathrm{e}} \\
\Delta \mathrm{G}=-\mathrm{RT} \operatorname{Ln} \mathrm{K}_{\mathrm{D}} \\
\operatorname{Ln} \mathrm{K}_{\mathrm{D}}=(\Delta \mathrm{S} / \mathrm{R})-(\Delta \mathrm{H} / \mathrm{RT})
\end{gathered}
$$

Table 3 summarizes the thermodynamic parameters associated the adsorption process. Values of $\Delta \mathrm{G}$ were calculated from the values of adsorption equilibrium constant $\left(\mathrm{K}_{\mathrm{D}}\right)$ using equations $7 \& 8$. The negative values of $\Delta \mathrm{G}$ at the three temperatures show that the adsorption process is spontaneous and the degree of spontaneity increases with increasing the temperature. The values of $\Delta \mathrm{H}$ and $\Delta \mathrm{S}$ are calculated from the slope and the intercept of the linear plot of $\mathrm{LnK}_{\mathrm{D}}$ vs. 1/T (Fig.8). The overall adsorption process seems to be endothermic $(\Delta \mathrm{H}=10.737 \mathrm{KJ} / \mathrm{mol})$. This result also supports the suggestion that the adsorption capacity of sesame increases with increasing temperature. Table 3 also shows that the $\Delta \mathrm{S}$ value is positive (entropy increases as a result of adsorption). A positive $\Delta \mathrm{S}$ value reflects the affinity of the adsorbent to the $\mathrm{Pb}$ ions, as a result of redistribution of energy between the adsorbate and adsorbent. Before adsorption occurs, the $\mathrm{Pb}$ ions near the surface of the adsorbent will be more ordered than in the subsequent adsorbed state and the ratio of free $\mathrm{Pb}$ ions to ions interacting with the adsorbent will; be higher in the adsorbed state (Mehmet, et al., 2007).

\subsection{Comparison with other adsorbents}

Numerous types of adsorbents have been tested for their ability to remove heavy metals. Batch adsorption experiments were done to assess the performance of chalf, rice husk, sesame husk, sun flower husk and tea waste 
as potential low-cost cellulose-containing natural adsorbents. The materials are readily available and relatively cheaper than synthetic resins. Table 4 details the summary of work done by various researchers, and the result of present work, using variety of agricultural waste materials for the removal of $\mathrm{Pb}$ ions. These biomasses include hemicellulose, lignin, extractives, lipids, proteins, simple sugars, water hydrocarbons, starch containing variety of functional groups that facilitates metal complexation which helps for the sequestering of heavy metals (Sud, et al., 2008). Data in table 4 revealed that the studied agricultural natural adsorbents showed high efficiency and selectivity for complexation with metal ions due to the following reasons:

(1) Large numbers of hydroxyl and amino groups.

(2) Primary amino groups provide high reactivity.

(3) The polymer chains provide suitable configurations.

The results showed that efficiencies of chalf, rice husk, sesame husk, sun flower husk and tea waste for $\mathrm{Pb}$ ion removal were $85 \%, 90 \%, 100 \%, 86 \%, 98 \%$. High adsorption capacity of the tested adsorbents makes it preferable and very attractive alternative adsorption material.

\section{Conclusion}

This paper highlighted the use of highly efficient low cost and abundant materials for removal of toxic $\mathrm{Pb}$ ions from contaminated aqueous solution. The rapid uptake and high capacity of chalf, rice husk, sesame, sun flower and tea waste indicated that it could be a better alternative for the removal of $\mathrm{Pb}$ (II) from real wastewater by sorption process. Kinetic experimental data revealed that intraparticular diffusion is not only the rate limiting step of the adsorption process. Kinetic, equilibrium and thermodynamic results revealed that $\mathrm{Pb}$ ion removal by the studied adsorbents proceeded through chemisorption and physisorption mechanisms. The results of equilibrium experiments indicated that removal efficiencies of the tested adsorbents were in the following order; sesame $>$ tea waste $>$ rice husk $>$ chalf $>$ sun flower. Based on the experimental conditions, it is found that the removal of $\mathrm{Pb}$ ion from their aqueous solution could attain $100 \%$. This shows a new trend for using agricultural wastes as a mean for wastes disposal for the benefit of environmental pollution control.

\section{References}

Adesola Babarinde N. A., Oyebamiji.Babalola J., \& Adebowale Sanni R. (2006). Biosorption of lead ions from aqueous solution by maize leaf, International Journal of Physical Sciences. 1, 023-026.

Ahluwalia S.S., \& Goyal D. (2005). Removal of heavy metals by waste tea leaves from aqueous solution, Engineering in Life Science, 5, 158-162.

Allen S.J., P.A. (1995). Brown, J. Chem. Tech. Biotechnol, 62, 17.

Amir H. M. Darush N., Forugh V., \& Sharokh N. (2005). Tea waste as an adsorbent for heavy metal removal from industrial wastewaters, American Journal of Applied Sciences, Vol, 2 (1) 372-375.

Brinza L., Nygård C.A., Dring M.J., Gavrilescu M., \& Benning L.G. (2009). Cadmium tolerance and adsorption by the marine brown alga Fucus vesiculosus from the Irish Sea and the Bothnian Sea, Bioresource Technology, $100,1727-1733$.

Davydova S. (2005). Heavy metals as toxicants in big cities, Microchemical Journal, 79, 133-136.

Hemn A. Smail, Kafia M. Shareef. Natural Soil as a Sorbent for removal of Non-ionic Surfactant from Ecosystem, $2^{\text {nd }}$ Iran International Zeolite Conference, April 29-30. Tehran, Iran.

Hiwa O. Ahmed, \& Kafia M. Shareef. (2010). Natural Soils as Adsorbent for removal of the Antibiotics from Polluted water, "Seventh International Conference on Material Sciences (CSM7), Beirut -Lebanon May 20-22.

Huda Yousif, Kafia M. Shareef. (2010). Rice Husk as a Low-cost Adsorbent for $\mathrm{Cu}$, Ni and $\mathrm{Zn}$ removal from Polluted Water, International Conference on Biology, Environment and Chemistry - ICBEC, 28-30 December, Hong Kong, China.

Huda. (2011). Msc. thesis, Department of chemistry, College of education, University of Salahaddin, Erbil.

Kafia M. Shareef \& George S. (2008). Sorption kinetics of 2,4-D and Carbaryl in selected agricultural soils of northern Iraq: application of a dual-rate model, Chemosphere, Vol. 72/1, pp. 8-15.

Kafia M. Shareef, \& Lawen A. Esmail. (2009). Competitive Adsorption of Heavy Metals by Natural Soils, $1^{\text {st }}$ International Conference on Engineering, Environment, Economy, Safety and Health, $10^{\text {th }}$ SENVAR, Manado, Indonesia, 26-27 November 2009. 
Karthika C., Vinnilamani N., Pattabhi S., \& Sekar M. (2010). Utilization of Sago Waste as an Adsorbent for the Removal of $\mathrm{Pb}$ (II) from Aqueous Solution: Kinetics and Isotherm Studies, International Journal of Engineering Science and Technology, Vol. 2 (6), 1867-1879.

Krishnan, K. A., \& Anirudhan, T. S.. (2003). Removal of cadmium (II) from aqueous solutions by steam activated sulphurised carbon prepared from sugar-cane bagasse pith: kinetics and equilibrium studied. Water SA., 29 (2).

Langergren K. Bil \& S. Ventenkapskad, (1898). Handl, 24 as cited by Trivedy et al, Adsorption of cellulose triacetate calcium silicate, J. Environ. Polym, 9, 525-529 (1973).

Lei Guo, Chang-mei sun, Gui-Ying Li, Chun-ping Lui, \& Chun-nuan Ji. (2009). Thermodynamics and kinetics of $\mathrm{Zn}$ (II) Adsorption on crosslinked starch phosphates, (2009). Journals of Hazardous Materials, Vol. 16 $150-155$.

Malakootian M., Nouri J., \& Hossaini H. (2009). Removal of heavy metals from paint industry's wastewater using Leca as an available adsorbent. Int. J. Environ. Sci. Tech., 6 (2), 183-190.

Maximous N, George F., \& Wan K. (2010). Removal of Heavy Metals from Wastewater by Adsorption and Membrane Processes: a Comparative Study, World Academy of Science, Engineering and Technology, 64.

Mehmet Emin Argun, Sukru Dursun, \& Mustafa Karatas. (2007). Heavy metal adsorption by modified Oak sawdust: Thermodynamic and Kinetics, Journal of Hazardous Materials, 141, 77-85.

Mittal A., D. Kaur \& J. Mittal. (2009). Journal of Hazardous Materials, 163, 568-577.

Mousavi H. Z., Hosseynifar A., Jahed V., Dehghani S. A. M. (2010). Removal of Lead from aqueous Solution using waste Tire Rubber Ash as an Adsorbent, Brazilian Journal of Chemical Engineering, Vol. 27, No. 01, pp. 79-87.

Najua, D. T., Luqman, C. A., Zawani, Z., \& Suraya, A. R. (2008). Adsorption of copper from aqueous solution by Elais Guineensis kernel activated carbon., J. Eng. Sci. Tech., 3 (2), 180-189.

Nasim A. K., Shaliza I., \& Piarapakaran S. (2004). Review paper; Elimination of Heavy Metals from Wastewater Using Agricultural,Wastes as Adsorbents, Malaysian Journal of Science, 23: 43 - 51.

Nassar M. M. (1997). The kinetics of basic dyes removal using palmfruit bunch, Adsorpt. Sci. Technol, 15(8): 609-617.

O. Badmus, K. Audu, \& U. Anyata. (2007). Removal of Lead Ion from Industrial Wastewaters by Activated Carbon Prepared from Periwinkle Shells (Typanotonus fuscatus), Turkish J. Eng. Env. Sci., 31. 251-263.

Pehlivan E., Altun T., \& Parlayici S. (2008). Utilization of barley straws as biosorbents for $\mathrm{Cu}^{2+}$ and $\mathrm{Pb}^{2+}$ ions, Journal of Hazardous Materials, doi:10.1016/j.jhazmat, 08.115, http://dx.doi.org/10.1016/j.jhazmat, 08.115.

Riaza M., Nadeema R., Hanifa M.A., Ansaric T.M., \& Rehmana K. (2009). Pb(II) biosorption from hazardous aqueous streams using Gossypium hirsutum (Cotton) waste biomass, Journal of Hazardous Materials, 161, $88-94$.

Rzepa G., Bajda T., \& Ratajczak T. (2009). Utilization of bog iron ores as sorbents of heavy metals, Journal of Hazardous Materials, 162, 1007-1013.

Sud D., Mahajan G., \& Kaur M. P. (2008). Agricultural waste material as potential adsorbent for sequestering heavy metal ions from aqueous solutions - A review, Bioresource Technology, 99, 6017-6027.

Vaghetti J.C.P., Lima E.C., B. Royer, da Cunha B.M., Cardoso N.F., Brasil J. L., \& Dias S.L.P. (2009). Pecan nutshell as biosorbent to remove $\mathrm{Cu}(\mathrm{II}), \mathrm{Mn}(\mathrm{II})$ and $\mathrm{Pb}(\mathrm{II})$ from aqueous solutions, Journal of Hazardous Materials, 162, 270-280.

Table 1. Kinetic parameters for $\mathrm{Pb}$ removal by sesame at $298 \mathrm{~K}, 0.08 \mathrm{~g} / 10 \mathrm{~mL}$ adsorbent dose

\begin{tabular}{|c|c|c|c|c|c|}
\hline $\mathrm{C} 0(\mathrm{mg} / \mathrm{L})$ & $\mathrm{q}_{\mathrm{e}(\exp )} \mathrm{mg} / \mathrm{g}$ & $\mathrm{q}_{\mathrm{e}(\mathrm{cal})} \mathrm{mg} / \mathrm{g}$ & $\Delta \mathrm{q}_{\mathrm{e}} \mathrm{mg} / \mathrm{g}$ & $\mathrm{K}_{\left(\min ^{-1}\right)}$ & $\mathrm{R}^{2}$ \\
\hline 15 & 1.88 & 0.346 & 1.534 & 0.0313 & 0.929 \\
\hline 25 & 2.63 & 1.997 & 0.633 & 0.0253 & 0.906 \\
\hline 50 & 4.50 & 3.480 & 1.020 & 0.0345 & 0.973 \\
\hline 75 & 5.44 & 4.419 & 1.021 & 0.0267 & 0.943 \\
\hline
\end{tabular}


Table 2. Regression parameters for Langmuire, Freundlich and Temkin adsorption isotherms for $\mathrm{Pb}$ removal by at $298 \mathrm{~K}, 0.08 \mathrm{~g} / 10 \mathrm{~mL}$ adsorbent dose

\begin{tabular}{|c|c|c|c|c|c|c|}
\hline $\begin{array}{c}\text { Isotherm } \\
\text { Models }\end{array}$ & $\begin{array}{c}\text { Adsorption } \\
\text { Parameters }\end{array}$ & Chalf & $\begin{array}{c}\text { Rice } \\
\text { husk }\end{array}$ & Sesame & $\begin{array}{c}\text { Sun } \\
\text { flower }\end{array}$ & $\begin{array}{c}\text { Tea } \\
\text { waste }\end{array}$ \\
\hline Langmuire & $\mathrm{q}_{\text {max. }}$ & 6.849 & 6.385 & 6.930 & 6.289 & 6.238 \\
\hline & $\mathrm{K}_{\mathrm{L}}$ & 0.083 & 0.123 & 0.208 & 0.091 & 0.221 \\
\hline & $\mathrm{R}^{2}$ & 0.961 & 0.961 & 0.961 & 0.973 & 0.963 \\
\hline Freundlich & & & & & & \\
\hline & $1 / \mathrm{n}$ & 0.407 & 0.395 & 0.334 & 0.386 & 0.232 \\
\hline & $\mathrm{K}_{\mathrm{F}}$ & 1.119 & 1.195 & 1.790 & 1.138 & 2.248 \\
\hline & $\mathrm{R}^{2}$ & 0.993 & 0.991 & 0.987 & 0.978 & 0.947 \\
\hline Temkin & & & & & & \\
\hline & $\mathrm{a}_{\mathrm{t}}$ & 0.218 & 0.309 & 1.451 & 0.348 & 2.342 \\
\hline & $\mathrm{b}_{\mathrm{t}}$ & 1.289 & 1.302 & 1.234 & 1.191 & 0.975 \\
\hline & $\mathrm{R}^{2}$ & 0.959 & 0.950 & 0.943 & 0.943 & 0.8701 \\
\hline
\end{tabular}

Table 3. Thermodynamic parameters for $\mathrm{Pb}$ removal by sesame at $0.08 \mathrm{~g} / 10 \mathrm{ml}$ adsorbent dose

\begin{tabular}{|c|c|c|c|c|c|}
\hline $\mathrm{T}(\mathrm{K})$ & $\mathrm{K}_{\mathrm{e}}$ & $\begin{array}{c}\Delta \mathrm{G} \\
(\mathrm{KJ} / \mathrm{mol})\end{array}$ & $\begin{array}{c}\Delta \mathrm{H} \\
(\mathrm{KJ} / \mathrm{mol})\end{array}$ & $\begin{array}{c}\Delta \mathrm{S} \\
(\mathrm{J} / \mathrm{mol})\end{array}$ & $\mathrm{R}^{2}$ \\
\hline 288 & 2.0966 & -1.772 & 10.733 & 43.626 & 0.9724 \\
\hline 298 & 2.5800 & -2.349 & & & \\
\hline 308 & 4.2300 & -3.688 & & & \\
\hline
\end{tabular}

Table 4. Comparison of adsorption capacity of different adsorbents for $\mathrm{Pb}$ ion removal

\begin{tabular}{|c|c|c|c|c|}
\hline $\begin{array}{c}\text { Agricultural } \\
\text { waste }\end{array}$ & $\begin{array}{c}\text { Adsorption } \\
\text { model }\end{array}$ & $\begin{array}{c}\text { Adsorption } \\
\text { capacity }\end{array}$ & $\begin{array}{c}\text { Removal } \\
\text { capacity }\end{array}$ & References \\
\hline Cotton waste & Langmuir & $44.67 \mathrm{mg} / \mathrm{g}$ & $90 \%$ & Riaz, et al., 2009 \\
\hline Maiz leaf & $\begin{array}{c}\text { Langmuir } \\
\text { Freundlich }\end{array}$ & & $>95 \%$ & $\begin{array}{c}\text { Adesola } \\
\text { Babarinde, et al., 2006 }\end{array}$ \\
\hline Pecan nutshell & $\begin{array}{c}\text { Redlich- } \\
\text { Peterson }\end{array}$ & $0.946 \mathrm{mmol} / \mathrm{g}$ & $>90 \%$ & Vaghetti, et al., 2009 \\
\hline Bog iron ores & Langmuir, & $97.0 \mathrm{mg} / \mathrm{g}$ & $>90 \%$ & Rzepa, et al., 2009 \\
\hline Tea leaves waste & Langmuir & & $96 \%$ & Ahluwalia \& Goyal, \\
\hline Barley straws & Langmuir & $23.20 \mathrm{mg} / \mathrm{g}$ & $80 \%$ & Pehlivan, et al., 2008 \\
\hline Chalf & Freundlich & & $85 \%$ & Present study \\
\hline Rice husk & Freundlich & & $90 \%$ & \\
\hline Sesame & Freundlich & & $100 \%$ & \\
\hline Sunflower & Freundlich & & $86 \%$ & \\
\hline Tea Waste & Freundlich & & $98 \%$ & \\
\hline
\end{tabular}




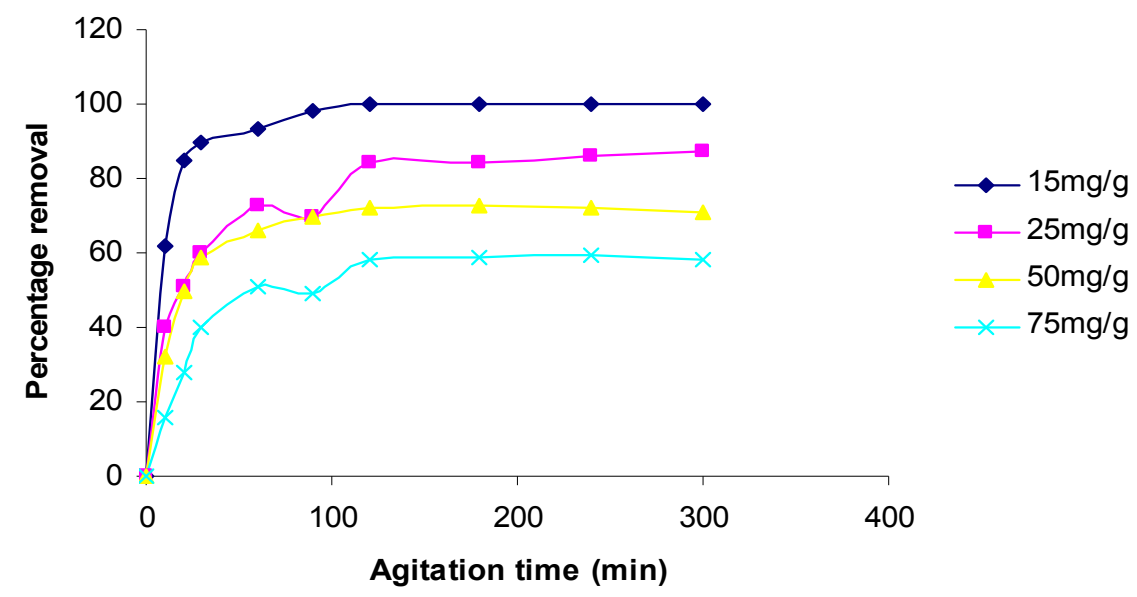

Figure 1. Effect of agitation time for $\mathrm{Pb}$ removal on the adsorption capacity of sesame at $298 \mathrm{~K}$, dose of adsorbent, $0.08 \mathrm{~g} / 10 \mathrm{ml}$

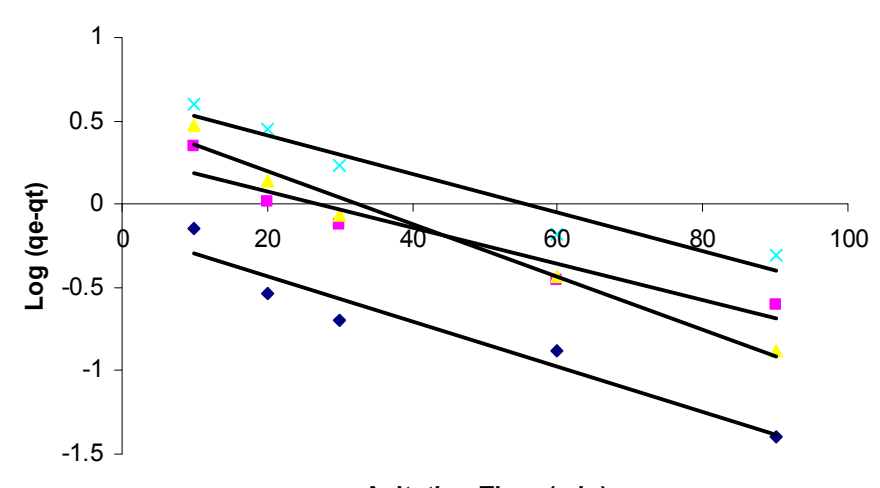

- $15 \mathrm{mg} / \mathrm{L}$

- $25 \mathrm{mg} / \mathrm{L}$

$50 \mathrm{mg} / \mathrm{L}$

$\times \quad 75 \mathrm{mg} / \mathrm{L}$

_Linear $(25 \mathrm{mg} / \mathrm{L})$

_ Linear (15 mg/L)

_ Linear $(50 \mathrm{mg} / \mathrm{L})$

_Linear $(75 \mathrm{mg} / \mathrm{L}$ )

Agitation Time (min)

Figure 2. Pseudo-first order plots for $\mathrm{Pb}$ removal by sesame at $298 \mathrm{~K}$, dose of adsorbent, $0.08 \mathrm{~g} / 10 \mathrm{~mL}$

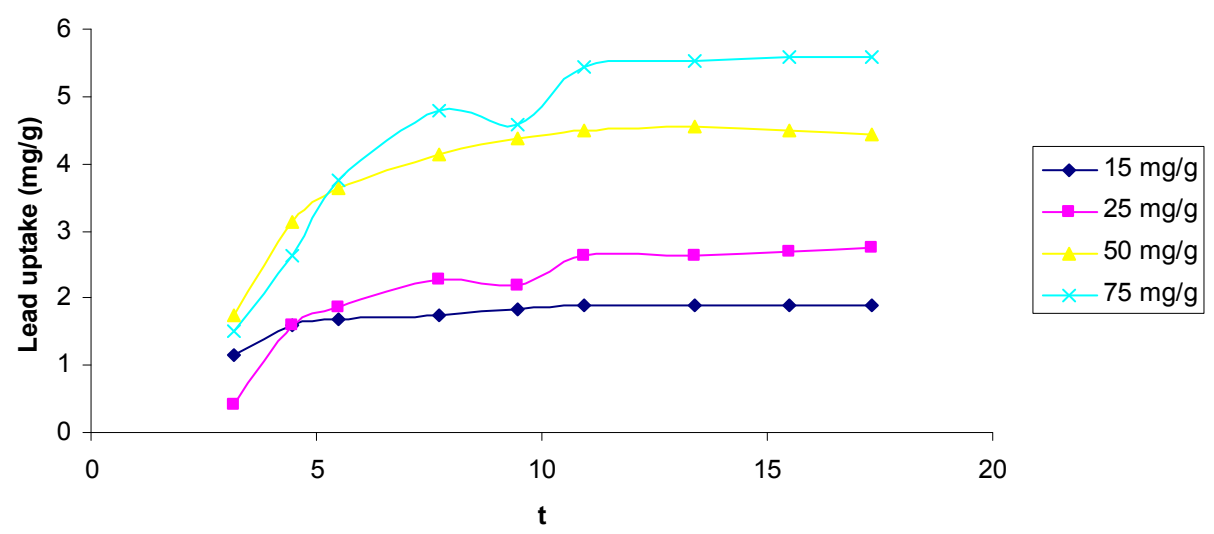

Figure 3. Plot of intraparticle diffusion kinetics for Pb removal by sesame at $298 \mathrm{~K}$, dose of adsorbent, $0.08 \mathrm{~g} / 10 \mathrm{~mL}$ 


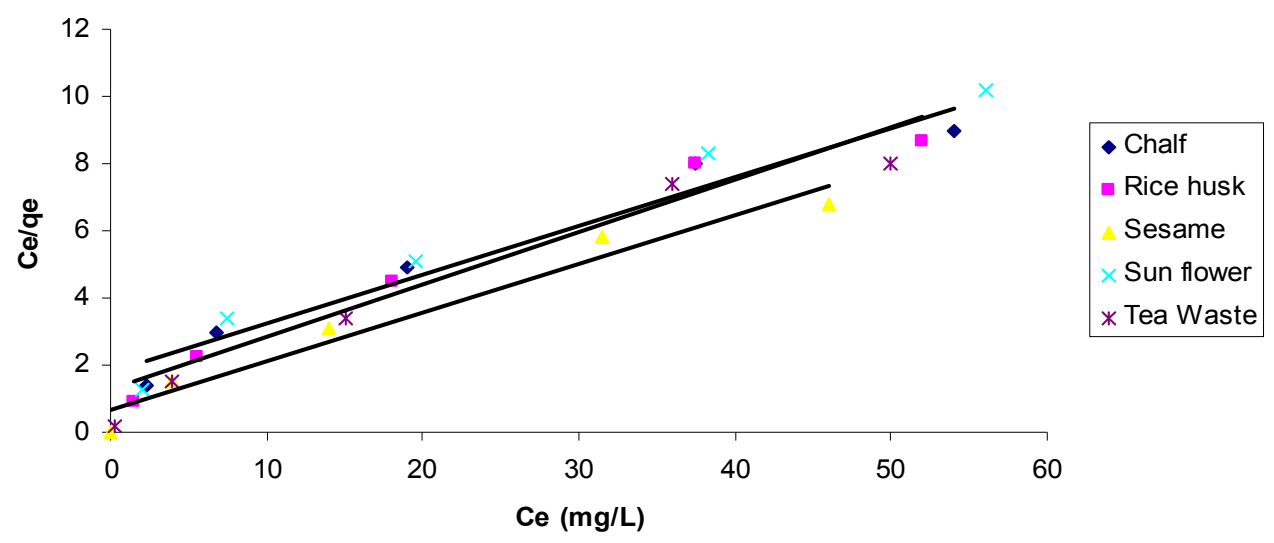

Figure 4. Langmuire isotherm for $\mathrm{Pb}$ ion removal at $298 \mathrm{~K}$, dose of adsorbent, $0.08 \mathrm{~g} / 10 \mathrm{~mL}$

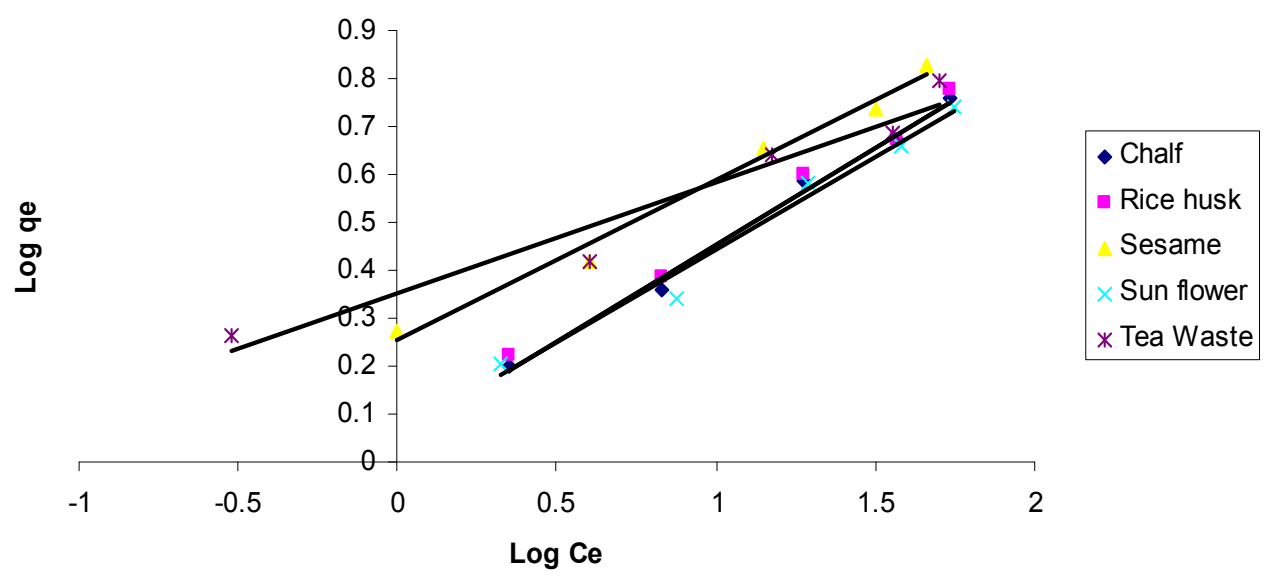

Figure 5. Freundlich isotherm for $\mathrm{Pb}$ ion removal at $298 \mathrm{~K}$, dose of adsorbent, $0.08 \mathrm{~g} / 10 \mathrm{~mL}$

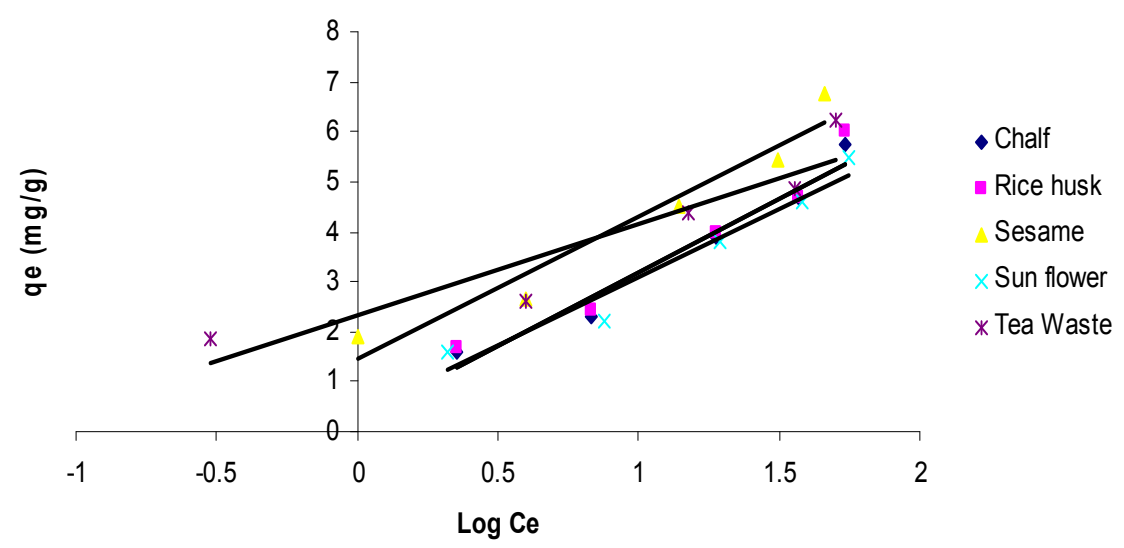

Figure 6. Temkin isotherm for $\mathrm{Pb}$ removal at $298 \mathrm{~K}, 0.08 \mathrm{~g} / 10 \mathrm{~mL}$ adsorbent dose 


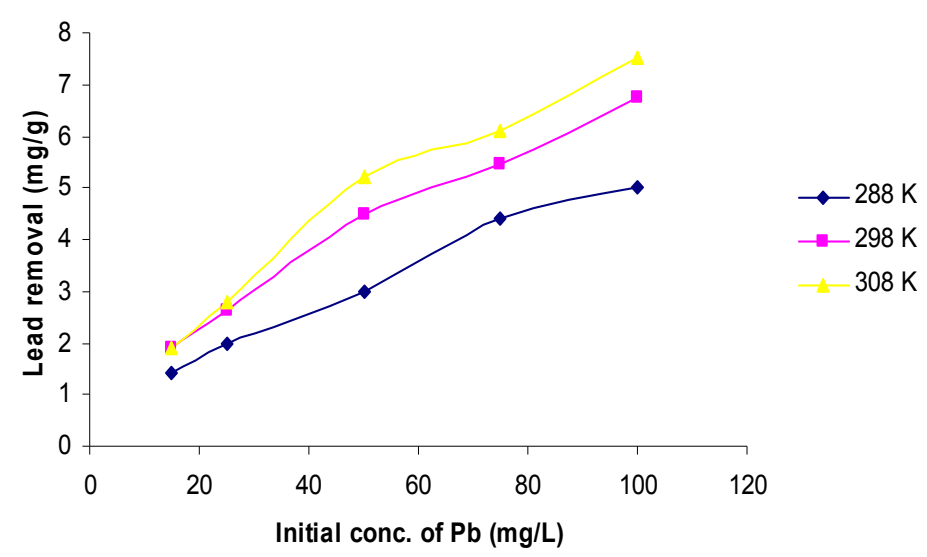

Figure 7. Effect of temperature on $\mathrm{Pb}$ ion removal by sesame at $298 \mathrm{~K}, 0.08 \mathrm{~g} / 10 \mathrm{~mL}$ adsorbent dose

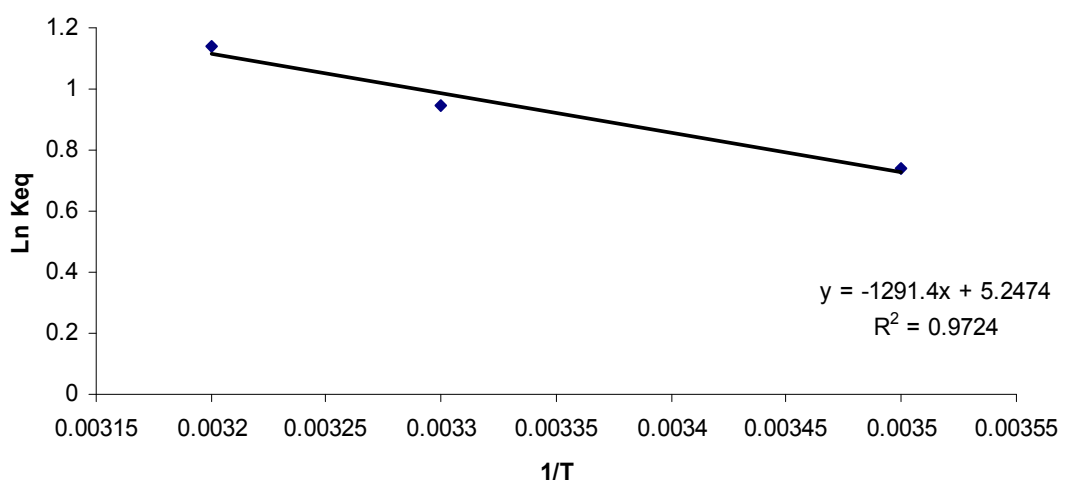

Figure 8. Plot of $\mathrm{Ln} \mathrm{K}_{\text {eq vs. }} 1 / \mathrm{T}$ for $\mathrm{Pb}$ ion removal by sesame at $298 \mathrm{~K}, 0.08 \mathrm{~g} / 10 \mathrm{~mL}$ adsorbent dose

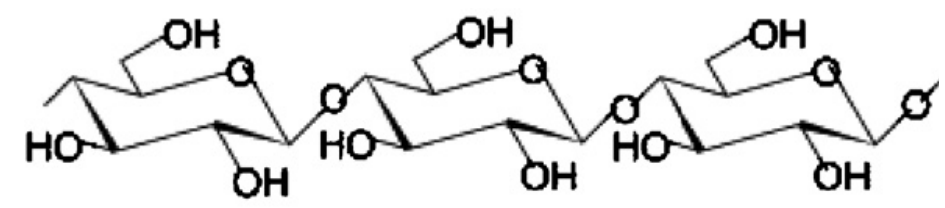

Figure 9. The structure of cellulose 